ORIGINAL ARTICLE

\title{
Anisometropic Amblyopia: Analysis of treatment results with patching of dominant eye and refraction with active visual therapy (AVT) in school age children.
}

\author{
Mohammad Alam', Lal Mohammad², Shaukat Khan ${ }^{3}$
}

Article Citation: Alam M, Mohammad L. Anisometropic Amblyopia: Analysis of treatment results with patching of dominant eye and refraction with active visual therapy of amblyopic eyes in school age children. Professional Med J 2022; 29(3):395-400.

https://doi.org/10.29309/TPMJ/2022.29.03.6742

ABSTRACT... Objectives: To analyse the results of Active Visual Therapy with patching and refraction in anisometropic amblyopia in school age children from age 7-15 years. Study Design: Analytical study. Setting: Department of Ophthalmology, DHQ KDA Teaching Hospital Kohat. Period: January 2016 to December 2018. Material \& Methods: The school age children suffering from anisometropic amblyopia with age range from 7-15 years. Proper documentation proforma was designed for record and follow up of patients. Informed consents were taken from parents of patients and they were specially trained for compliance. Total 41 patients were included comprising $28(68.29 \%)$ male and $13(31.70 \%)$ female with age range of $7-15$ years. Anterior and posterior segments were properly examined. Best corrected visual therapy was recorded. Difference of two or more lines on snellen chart between the two eyes was considered to be anisometropic amblyopia. Before treatment $14(34.14 \%)$ patients had BCVA of $6 / 24,8(19.51 \%)$ patients had $6 / 36,10(24.39 \%)$ patients had $6 / 60$ and $9(21.95 \%)$ patients had CF. Out of 41 patients $29(70.73 \%)$ patients were hypermetropic while $12(29.26 \%)$ were myopic. The refractive error of amblyopic eyes in spherical equivalent was from +7 to -5 diopters. Proper refractive correction was done. Patching of the normal eye was advised for three hours per day at the dose of one week per year of age. The amblyopic eye was exposed to active visual therapy with video games with computer and smart phones. The patients were examined after each three months and improvement in visual acuity and change in refraction was addressed. Results were analysed on the basis of pretreatment and post treatment visual acuity. Finally T-test for regression and co-relation was applied on the post treatment status of visual acuity of $6 / 24,6 / 36,6 / 60$ and Counting finger with pretreatment status of visual acuity of 6/24, 6/36, 6/60 and Counting finger showing $\mathrm{P}=0.005$ which is less than 0.05 and is statistically significant. Results: Cumulatively after treatment out of 41 patients $10(24.39 \%)$ had best corrected visual acuity $6 / 6,6(14.63 \%)$ had $6 / 9,7(17.07 \%)$ had $6 / 12,7(17.07 \%)$ had $6 / 18,4(9.75 \%)$ had $6 / 24,5(12.19 \%)$ had $6 / 60$ and $2(4.87 \%)$ had best corrected visual acuity of CF. Conclusion: Patching of dominant eye and refraction with Active Visual Therapy of amblyopic eye is effective in treatment of anisometropic amblyopia.

Kew words: $\quad$ Active Visual Therapy (AVT), Best Corrected Visual Acuity (BCVA), Counting Fingers (CF), Visual Acuity (V.A).

\section{INTRODUCTION}

Amblyopia is defined is sub normal development of vision due to developmental defect of spatial processing of vision in the central nerve visual pathway of brain. ${ }^{1}$ Majority of cases of monocular visual disability is due to amblyopia. ${ }^{2}$ If this disability is passed undetected, it results in permanent visual impairment.

Anisometropic amblyopia is the difference of inter ocular refractive error such that the plain of focus for both eyes is different. Most of the ophthalmologists are in the opinion that one diopter difference between the two is required to define anisometropic amblyopia. ${ }^{3,4}$ But this difference varies between 0.5 diopter and two diopter. $5,6,7$ The prevalence of anisometropic amblyopia ranges from $1 \%$ to $1.65 \% .^{8}$ Although there are various types of amblyopia like anisometropic, strabismic, stimulus deprivation, meridional, anisometropic amblyopia contributes one third of amblyopia. ${ }^{9}$

Differences are their among these amblyopia
1. FCPS, Associate Professor Ophthalmology, Khyber Medical University Institute of Medical Sciences Kohat. 2. FCPS, Professor Ophthalmology, Khyber Medical University Institute of Medical Sciences Kohat.

3. MSc (Clinical Optometry), Doctor of Optometry Department of Ophthalmology, KDA Teaching Hospital, Kohat.

\author{
Correspondence Address: \\ Dr. Mohammad Alam \\ Department of Ophthalmology \\ Khyber Medical University Institute of Medical \\ Sciences Kohat. \\ malamktk@gmail.com
}

Article received on:

Accepted for publication:

$13 / 08 / 2021$ $27 / 10 / 2021$ 
but research based out comes may not differentiate. ${ }^{10,11}$ Previously amblyopia was thought to be incurable but resent research has proved that ophthalmologists had partial understanding of the plasticity of visual system of human brain and anisometropic amblyopia patients can also get benefit from appropriate therapy. ${ }^{12}$ There are various methods of treating anisometropic amblyopia like penalization with atropine, patching of the dominant eye, refraction with AVT of amblyopic eye which might help in the treatment. AVT in the form of video game therapy is quite helpful in the treatment of anisometropic amblyopia. ${ }^{13}$

Standard protocol of amblyopia treatment is occlusion therapy involving patching of the dominant eye while encouraging amblyopic eye to be used for vision. This therapy is effective in $75 \%$ of children showing improvement of visual acuity. ${ }^{14}$ However, the results decreases with increasing age. The conventional treatment of anisometropic amblyopia has been augmented with new approaches like video games to stimulate and activate neuro modulatory pathway of central visual system. ${ }^{15}$

Specifically active AVT based on perceptual learning with patching of dominant eye and video game with amblyopic eye is an interesting with new area of research that can complement and optimize conventional methods treatment of anisometropic amblyopia. ${ }^{16,17}$

\section{MATERIAL \& METHODS}

This study was conducted in Department of Ophthalmology, DHQ KDA Teaching Hospital Kohat from January 2016 to December 2018 on school age children suffering from anisometropic amblyopia with age range from 7-15 years the study was approved by ethical committee of institution (KIMS/Estt/480). Proper documentation proforma was designed for record and follow up of patients. Informed consents were taken from parents of patients and they were specially trained for compliance and follow up.

\section{RESULTS}

Total 55 patients were selected for the study.
However during treatment and follow up phase 14 patients were lost. Hence 41 patients who completed the treatment were included in the study comprising $28(68.29 \%)$ male and $13(31.70 \%)$ female with age range of $7-15$ years (Table-I). Anterior and posterior segments were properly examined. Best corrected visual therapy was recorded. Difference of two or more lines on snellen chart between the two eyes was considered to be anisometropic amblyopia. Out of 41 patients $29(70.73 \%)$ were hypermetropic while 12(29.29\%) were myopic (Table-II). Before treatment $14(34.14 \%)$ patients had BCVA of $6 / 24,8(19.51 \%)$ patients had $6 / 36,10(24.39 \%)$ patients had $6 / 60$ and $9(21.95 \%)$ patients had CF (Table-III). Proper refractive correction was done. Refractive error of amblyopic eyes in spherical equivalent was from +7 to -5 diopters. Patching of the normal eye was advised for three hours per day at the dose of one week per year of age. The amblyopic eye was exposed to active visual therapy with video games with computer and smart phones. The patients were examined after each three months and improvement in visual acuity and change in refraction was addressed. Results were analyzed on the basis of pretreatment visual acuity. Finally T-test for regression and corelation was applied on the post treatment status of visual acuity of $6 / 24,6 / 36,6 / 60$ and CF with pretreatment status of visual acuity of $6 / 24,6 / 36$, $6 / 60$ and $C F$ showing $P=0.005$ which is less than 0.05 and is statistically significant.

In 14 patients of visual acuity 6/24, 7(50\%) achieved BCVA of $6 / 6,3(21.42 \%)$ had $6 / 9$, and $4(28.57 \%)$ had achieved BCVA of 6/12 (Table-IV).

In 8 patients of visual acuity 6/36, 3(37.5\%) achieved BCVA of $6 / 6,3(37.5 \%)$ had $6 / 9,1(12.5 \%)$ patients had of $6 / 12$, and1 (12.5\%) achieved BCVA 6/18 (Table-V).

In 10 patients of visual acuity 6/60, 2 (20\%) achieved BCVA 6/12, 6 (60\%) had 6/18, 1(10\%) had 6/24 and 1(10\%) had BCVA 6/60 (Table-VI).

Out of 9 patients of visual acuity CF, $3(33.33 \%)$ achieved 6/24, 4(44.44\%) had 6/60, and 2(22.22\%) BCVA CF (Table-VII). 
Cumulatively after treatment out of 41 patients 10(24.39\%) patients had BCVA 6/6, 6(14.63\%) had $6 / 9,7(17.07 \%)$ had $6 / 12,7(17.07 \%)$ had $6 / 18,4(9.75 \%)$ had $6 / 24,5(12.19 \%)$ had $6 / 60$ and $2(4.87 \%)$ patients had BCVA of CF (Table-VIII).

\begin{tabular}{|l|c|}
\hline \multicolumn{1}{|c|}{ Gender } & Number of Patients (\%) \\
\hline Male & $28(68.29 \%)$ \\
\hline Female & $13(31.70 \%)$ \\
\hline
\end{tabular}

Table-I. Gender distribution. Number of patients-41.
Refractive Error

Number of Patients (\%)

Hypermetropia

Myopia

$12(29.26 \%)$
Table-II. Refractive error. Number of patients-41.

\begin{tabular}{|l|c|}
\hline \multicolumn{1}{|c|}{ Visual Acuity Groups } & Number of Patients (\%) \\
\hline $6 / 24$ & $14(34.14 \%)$ \\
\hline $6 / 36$ & $8(19.51 \%)$ \\
\hline $6 / 60$ & $10(24.39 \%)$ \\
\hline CF & $9(21.95 \%)$ \\
\hline
\end{tabular}

Table-III. Pretreatment V.A groups. Number of patients-41.

\begin{tabular}{|l|c|}
\hline \multicolumn{1}{|c|}{ Visual Acuity } & Number of Patients \\
\hline $6 / 6$ & $7(50 \%)$ \\
\hline $6 / 9$ & $3(21.42 \%)$ \\
\hline $6 / 12$ & $4(28.57 \%)$ \\
\hline $6 / 18$ & $0(0 \%)$ \\
\hline $6 / 24$ & $0(0 \%)$ \\
\hline $6 / 36$ & $0(0 \%)$ \\
\hline $6 / 60$ & $0(0 \%)$ \\
\hline CF & $0(0 \%)$ \\
\hline
\end{tabular}

Table-IV. Post treatment results of VA 6/24 group. Number of patients. 14 .

\begin{tabular}{|l|c|}
\hline \multicolumn{1}{|c|}{ Visual Acuity } & Number of Patients \\
\hline $6 / 6$ & $3(37.5 \%)$ \\
\hline $6 / 9$ & $3(37.5 \%)$ \\
\hline $6 / 12$ & $1(12.5 \%)$ \\
\hline $6 / 18$ & $1(12.5 \%)$ \\
\hline $6 / 24$ & $0(0 \%)$ \\
\hline $6 / 36$ & $0(0 \%)$ \\
\hline $6 / 60$ & $0(0 \%)$ \\
\hline CF & $0(0 \%)$ \\
\hline
\end{tabular}

Table-V. Post treatment results of VA 6/36 group. Number of patients. 8.

\begin{tabular}{|l|c|}
\hline \multicolumn{1}{|c|}{ Visual Acuity } & Number of Patients \\
\hline $6 / 6$ & $0(0 \%)$ \\
\hline $6 / 9$ & $0(0 \%)$ \\
\hline $6 / 12$ & $2(20 \%)$ \\
\hline $6 / 18$ & $6(60 \%)$ \\
\hline $6 / 24$ & $1(10 \%)$ \\
\hline $6 / 36$ & $0(0 \%)$ \\
\hline $6 / 60$ & $1(10 \%)$ \\
\hline CF & $0(0 \%)$ \\
\hline
\end{tabular}

Table-VI. Post treatment results of VA 6/60 group. Number of patients. 10.

\begin{tabular}{|l|c|}
\hline \multicolumn{1}{|c|}{ Visual Acuity } & Number of Patients \\
\hline $6 / 6$ & $0(0 \%)$ \\
\hline $6 / 9$ & $0(0 \%)$ \\
\hline $6 / 12$ & $0(0 \%)$ \\
\hline $6 / 18$ & $0(0 \%)$ \\
\hline $6 / 24$ & $3(33.33 \%)$ \\
\hline $6 / 36$ & $0(0 \%)$ \\
\hline $6 / 60$ & $4(44.44 \%)$ \\
\hline CF & $2(22.22 \%)$ \\
\hline
\end{tabular}

Table-VII. Post treatment results of VA CF group. Number of patients. 9.

\begin{tabular}{|l|c|c|}
\hline Visual Acuity & Number of Patients & \%age \\
\hline $6 / 6$ & $10(24.39 \%)$ & \\
\hline $6 / 9$ & $6(14.63 \%)$ & \\
\hline $6 / 12$ & $7(17.07 \%)$ & \\
\hline $6 / 18$ & $7(17.07 \%)$ & \\
\hline $6 / 24$ & $4(9.75 \%)$ & \\
\hline $6 / 36$ & $0(0 \%)$ & \\
\hline $6 / 60$ & $5(12.19 \%)$ & \\
\hline CF & $2(4.87 \%)$ & \\
\hline
\end{tabular}

Table-VIII. Post treatment cumulative results. Number of patients. 41.

\section{DISCUSSION}

Active visual therapy (AVT) with patching is the gold standard treatment of anisometropic amblyopia. Our study shows accountable results with AVT in the treatment of anisometropic amblyopia as reflected in results table. Results mainly depends on severity of amblyopia, age of patients and compliance of therapy. Tables-IV and $\mathrm{V}$ mentioning VA $6 / 24$ and $6 / 36$ with less severe amblyopia demonstrate accountable outcome as compared to severe amblyopia as shown in Tables-VI and VII. In more dense amblyopia in 
our patients with pretreatment visual acuity of counting finger $22.2 \%$ patents have shown no improvement. Multiple national and international studies have been carried out on this issue with variable results but all studies favour patching of dominant eye with AVT of amblyopic eye to be the best one. The national and international results variations are mainly AVT duration, age of patient's degree and depth of amblyopia and compliance of treatment. In our study the AVT time was 3 hours per day at the dose of one week per year of age while literature review shows AVT duration of $2-6$ hours daily in various studies.

Reversal of anisometropic amblyopia is possible if during the sensitive period of visual development proper visual stimulus is provided. Several randomized controlled clinical studies have elicited the results of patching and AVT duration.

PEDIG Trial of 6 hours, full time occlusion have shown improvement of various degree in amblyopic therapy ${ }^{14}$ and the results depend upon the severity of amblyopia. ${ }^{18}$

PRDIG has shown 3.6 lines improvement in ampblyopia with 2 hours patching while in our study 3 hours patching was done with AVT. ${ }^{19}$

Wallace DK, Laizar EL, study recommends that if improvement in visual acuity stops with 2 hours patching then duration should be increased to 8 hours patching and that will improve the visual acuity. ${ }^{20}$

Singh et al have reported significant differences between patching and patching with AVT. The only patching has shown 1.8 line improvement while patching with AVT has shown improvement of 2.4 lines supporting our study. ${ }^{21}$

Carlos $J$ Hernandiz Rodriguez etal in their randomized control trial has reported promising results of AVT patching in anisometropic amblyopia. $^{22}$

The treatment outcomes mainly depend upon age of the patient refractive error and compliance of patients.Poor compliance with treatment increases the risk of treatment failure. Oliver et al and Chen et al have found younger amblyopic more compliant than older amblyopic and show good results with therapy. ${ }^{23,24}$

Lithander J, Sjostrand have reported that compliance influences the outcome of therapy very much and with good compliance resolution of amblyopia is $95 \%$ as compared to poor compliance in which resolution of amblyopia is $50 \% .^{25}$

S. S Toor et al have reported in their study the age, degree of anisometropia, depth of amblyopia, treatment modality and compliance of treatment were the major factors responsible for success and failure in management of anisometropic amblyopia. ${ }^{26}$

\section{CONCLUSION}

Anisometropic amblyopia is a quite treatable ocular morbidity particularly when patching of dominant eye is augmented with active visual therapy of the amblyopic eye. The reversal of amblyopia is co-related with many factors. Age of the patient and severity of amblyopia are important factors which direct effect on reversal. Early age and less severe amblyopia have good results with patching and active visual therapy. Compliance of treatment is also important factor in reversal of amblyopia. Good compliance is necessary for fruitful results.

Copyright $@ 27$ Oct, 2021.

\section{REFERENCES}

1. Eggers HM. Amblyopia. In: Diamond GR, Eggers HM, eds. Strabismus and pediatric ophthalmology Vol $\mathbf{5}$. In: Podos SM, Yanoff M, eds. Textbook of ophthalmology. London: Mosby, 1993; pp 13.1-13.17.

2. National Eye Institute. Amblyopia (Home page on internet). Maryland, United States of America: National Eye Institute. (Online) Updated 2011 Sep 23. (Cited 2011 Sep 24). Available form URL: http://www.nig.gov/ health/amblyopia/amblyopia_guide. asp.

3. Steward CE, Moseley MJ, Fielder AR, Stephens DA, MOTAS cooperative. Refractive adaptation in amblyopia: Quantification of effect and implications for practice. Br J Ophthalmol 2004; 88: 1552-1556. 
4. Huynh SC, Wang XY, Ip J, Robaci D, Kifley A, Rose KA, et al. Prevalence and associations of anisometropia and aniso-astigmatism in a population based sample of 6 years old children. BR J Ophthalmol 2006; 90: 597-601.

5. Malik SRK, Gupta AK, Choudhry S. Anisometropia: Its relation to amblyopia and eccentric fixation. $\mathrm{Br} \mathrm{J}$ Ophthalmol 1968; 52:773-776.

6. Cobb CJ, Russell K, Cox A, MacEwen CJ. Factors influencing visual outcome in anisometropic amblyopes. $\mathrm{Br} \mathrm{J}$ Ophthalmol 2002; 86: 1278-1281.

7. De Vries J. Anisometropia in children: Analysis of a hospital population. $\mathrm{Br} \mathrm{J}$ Ophthalmol 1985; 69: 504507.

8. Almeder LM, Peck LB, Howland HC. Prevalence of anisometropia in volunteer laboratory and school screening populations. Invest Ophthalmol Vis Sci 1990; 31: 2448-2455.

9. Pediatric Eye Investigator Group (PEDIG). The clinical profile of moderate amblyopia in children younger than 7 years. Arch Ophthalmol 2002; 120: 281-287.

10. Oliver M, Nawartzki I. screening of pre-school children for ocular anomalies. II. Amblyopia. Prevalence and therapeutic results at different ages. $\mathrm{Br} \mathrm{J}$ Ophthalmol 1971; 55: 467-471.

11. Hug T. Full-time occlusion compared to part-time occlusion for the treatment of amblyopia. Optometry 2004; 75: 241-244.

12. Astle At, McGraw PV, Webb BS. Can human amblyopia be treated in adulthood? Strabismus 2011; 19:99-109.

13. Li Rw, Ngo C. Nguyen J, Levi DM. Videogame play induces plasticity in the visual system of adults with amblyopia. PLoS Biol 2011; 9:e1001-135.

14. Repka MX, Beck RW, Holmes JM, et al. Pediatric eye disease investigator group. A randomized trial of patching regimens for treatment of moderate amblyopia in children. Arch Ophthalmol. 2003; 121 : 603-611.

15. Dye MW, Green CS, Bavelier D. The development of attention skills in action video game players. Neuropsychologia. 2009 Jul 1; 47(8-9):1780-9.
16. Kraus $C L$, Culican SM. New advances in amblyopia therapy I: binocular therapies and pharmacologic augmentation. British Journal of Ophthalmology. 2018 Nov $1 ; 102(11): 1492-6$.

17. Foss AJ. Use of video games for the treatment of amblyopia. Current Opinion in Ophthalmology. 2017 May $1 ; 28(3): 276-81$.

18. Holmes JM, Kraker RT, Beck RW, et al. A randomized trial of prescribed patching regimens for treatment of serve amblyopia in children. Ophthalmology 2003; 110: $2075-87$.

19. Pediatric Eye Disease Investigator Group. A randomized trial of near versus distance activities while patching for amblyopia in children aged 3 to less than 7 years. Ophthalmology 2008; 115:2071-8.

20. Wallace DK, Lazar EL, Crouch ER 3rd, et al. Time course and predictors of amblyopia improvement with 2 hours of daily patching. JAMA Ophthalmol 2015; 133:606-9.

21. Singh A, Sharma $P$, Saxena R. Evaluation of the role of monocular video game play as an adjuvant to occlusion therapy in the management of anisometropic amblyopia. Journal of Pediatric Ophthalmology \& Strabismus. 2017 Jul 1; 54(4):244-9.

22. Carlos J, Rodriguez.H, David P. Active vision therapy for anisometropic amblyopia in children: A systematic review. Journal of Ophthalmology Volume 2020.Article ID 4282316,9 pages. https//doi. org/10.1155/2020/4282316.

23. Oliver M, Neumann R, Chaimovitch $\mathrm{Y}$, Gotesman N, Shimshonni M. Compliance and results of treatment for amblyopia in children more than 8 years old. Am J Ophthalmol 1986; 102: 340-345.

24. Chen P-L, Chen J-T, Tai M-C, Fu J-J, Chang C-C, Lu D-W. Anisometropic amblyopia treated with spectacle correction alone: possible factors predicting success and time to start patching. Am J Ophthalmol 2007; 143: 54-60.

25. Lithander J, Sjostrand J. Anisometropic and strabismic amblyopia in the age group 2 years and above: $A$ prospective study of the results of treatment. $\mathrm{Br} \mathrm{J}$ Ophthalmol 1991; 75: 111-116.

26. S S Toor, Anna M, Patricia M et al. Anisometropic amblyopia: Factors influencing the success or failure of its treatment. Br J Orthopt J 2012; 9:9-16. 
AUTHORSHIP AND CONTRIBUTION DECLARATION

\begin{tabular}{c|l|l|l|} 
No. & \multicolumn{1}{|c|}{ Author(s) Full Name } & \multicolumn{1}{|c|}{ Contribution to the paper } & Author(s) Signature \\
\hline 1 & Mohammad Alam & Principal author \\
\hline 2 & Lal Mohammad & Co-author \\
3 & Shaukat Khan & Co-author & \\
\hline
\end{tabular}

